\title{
Artemisinin combination therapy can result in clinical failure if oral therapy is not directly observed
}

\author{
Wilson W Chan $\mathrm{MD}^{1,2}$, Divya Virmani $\mathrm{MD}^{3}$, Dylan R Pillai MD PhD $\mathrm{P}^{1,2,3}$
}

\begin{abstract}
WW Chan, D Virmani, DR Pillai. Artemisinin combination therapy can result in clinical failure if oral therapy is not directly observed. Can J Infect Dis Med Microbiol 2013;24(4):215-216.

Intravenous artesunate therapy is the first-line therapy for severe malaria, and is highly efficacious when used in combination with an oral partner drug such as doxycycline or atovaquone-proguanil. However, treatment failure occurs routinely with artesunate monotherapy due to the very short half-life of this drug. In North America, experience with artesunate is limited. With the pressure to discharge patients early, administration of the essential oral partner drug is often left to the discretion of the patient. Thus, treatment failure may be commonplace if nonadherence is a factor, as was observed in the case described in the present report.
\end{abstract}

Key Words: Adherence; Artesunate; Malaria; Plasmodium falciparum; Treatment failure

\section{Risque d'échec clinique de la thérapie associative à l'artémisinine si le traitement oral n'est pas rigoureusement observé}

L'artésunate par voie intraveineuse, le traitement de première ligne du paludisme sévère, est très efficace lorsqu'on l'utilise en association avec un médicament complémentaire par voie orale, comme la doxycycline ou l'atovaquone-proguanil. Cependant, à cause de sa très courte demivie, l'artésunate échoue régulièrement en monothérapie. En Amérique du Nord, on a peu d'expérience de l'artésunate. En raison des pressions exercées pour donner rapidement leur congé aux patients, l'administration essentielle du médicament complémentaire par voie orale est souvent laissée au gré du patient. L'échec thérapeutique peut être courant en cas de non-observance, comme on l'a constaté dans le présent rapport de cas.

\section{CASE PRESENTATION}

A case involving a 26-year-old woman from Sudan in the winter of 2011 is presented. During her immigration flight from Sudan via Frankfurt, Germany to Calgary, Alberta, she began to experience fevers and abdominal pain. From the airport, she presented directly to the emergency room (ER) on day 0 , where she was afebrile with normal vital signs. She was diagnosed with gastroenteritis and discharged home. Over the next three days, she developed fever with chills and rigors, anorexia, vomiting, myalgias and increasing confusion. She had recently tested negative for HIV before immigration.

On day 3 , she returned and was febrile (temperature $38.6^{\circ} \mathrm{C}$ ), tachycardic, normotensive and required $5 \mathrm{~L} / \mathrm{min} \mathrm{O}_{2}$ to maintain $\mathrm{O}_{2}$ saturation. Scleral icterus and nuchal rigidity were noted. She had moderate abdominal tenderness but no peritoneal signs. Investigations revealed a hemoglobin level of $115 \mathrm{~g} / \mathrm{L}$, platelet count of $27 \times 10^{9} / \mathrm{L}$ and leukocyte count of $8.3 \times 10^{9} / \mathrm{L}$. Her electrolyte, creatinine and liver transaminase levels were normal, lactate dehydrogenase level was $943 \mathrm{U} / \mathrm{L}$ and total bilirubin level was $42.75 \mu \mathrm{mol} / \mathrm{L}$. She was started on empirical meningitis treatment with ceftriaxone. A lumbar puncture was deferred because of her low platelet count. Computed tomography scanning of the head was normal; a computed tomography scan of the abdomen revealed borderline hepatomegaly and splenomegaly. A set of malaria smears drawn that evening identified $2.1 \%$ Plasmodium falciparum. Because of her confusion and impaired level of consciousness, the patient was classified as a severe case of malaria (1). Artemisinin combination therapy is the first-line therapy in North America for severe and complicated malaria, and she was started on artesunate $2.4 \mathrm{mg} / \mathrm{kg}$ (190 mg) intravenously every $12 \mathrm{~h}$, given at $0 \mathrm{~h}, 12 \mathrm{~h}, 24 \mathrm{~h}$ and $48 \mathrm{~h}$ (1). Repeat malarial smears were performed, showing an increasing parasitemia that peaked at $6.6 \%$ on day 4 but decreased to $0.3 \%$ after treatment on the same day, and was undetectable by day 5 .
The patient improved cognitively and symptomatically after $48 \mathrm{~h}$. She was closely monitored for hypoglycemia, acute renal failure and acute respiratory distress syndrome, but these did not manifest. After completing her course of parenteral artesunate on day 5 , the patient was started on a course of atovaquone-proguanil for an additional four days. She received one dose in hospital and was then discharged on day 7 with a prescription for three more days. She was also to receive seven additional days of ceftriaxone through a home parenteral therapy program. At the time of discharge, the patient's platelet count had recovered to $130 \times 10^{9} / \mathrm{L}$ and hemoglobin level had risen to $88 \mathrm{~g} / \mathrm{L}$ from a nadir of $77 \mathrm{~g} / \mathrm{L}$ on day 5 . When seen in follow-up in the outpatient parenteral therapy clinic on day 12 , she was feeling well.

On day 31 after onset of illness, the patient again presented to the ER, complaining of two weeks of fevers, chills, nausea and vomiting, and intermittent right upper quadrant abdominal pain. Her husband insisted that she had completed her course of atovaquone-proguanil. Vital signs showed a temperature of $38.9^{\circ} \mathrm{C}$ and tachycardia (heart rate 134 beats $/ \mathrm{min}$ ), with normal blood pressure and $\mathrm{O}_{2}$ saturation at room air. Abdominal examination revealed tenderness to percussion and dullness over Castell's point. The rest of her examination was unremarkable. At this time, her hemoglobin level was $115 \mathrm{~g} / \mathrm{L}$, platelet count was $97 \times 10^{9} / \mathrm{L}$ and leukocyte count was $7.3 \times 10^{9} / \mathrm{L}$. Electrolyte, creatinine and liver transaminase levels were normal. Bilirubin and lactate dehydrogenase levels were elevated $(27.4 \mu \mathrm{mol} / \mathrm{L}$ and $384 \mathrm{U} / \mathrm{L}$, respectively). Blood cultures were negative, but her malaria smears were once again positive for $P$ falciparum, with a parasitemia of $3.5 \%$. The patient was diagnosed with recrudescent malaria and started on artesunate therapy $(2.4 \mathrm{mg} / \mathrm{kg}$ intravenously every $12 \mathrm{~h})$ again. Repeat malaria smears revealed a drop in parasitemia to $2.0 \%$ after $8 \mathrm{~h}$ and became negative in subsequent smears. She was treated for $48 \mathrm{~h}$ with parenteral artesunate, followed by a course of doxycycline $(100 \mathrm{mg}$

${ }^{1}$ Calgary Laboratory Services; ${ }^{2}$ Department of Pathology $\mathcal{E}$ Laboratory Medicine; ${ }^{3}$ Division of Infectious Diseases, Department of Medicine, University of Calgary, Calgary, Alberta

Correspondence: Dr Dylan R Pillai, University of Calgary, Diagnostic Eु Scientific Centre, Room 1W-416, 9-3535 Research Road Northwest,

Calgary, Alberta T2L 2K8. Telephone 403-770-3578, fax 403-770-3347, e-mail dylan.pillai@cls.ab.ca 


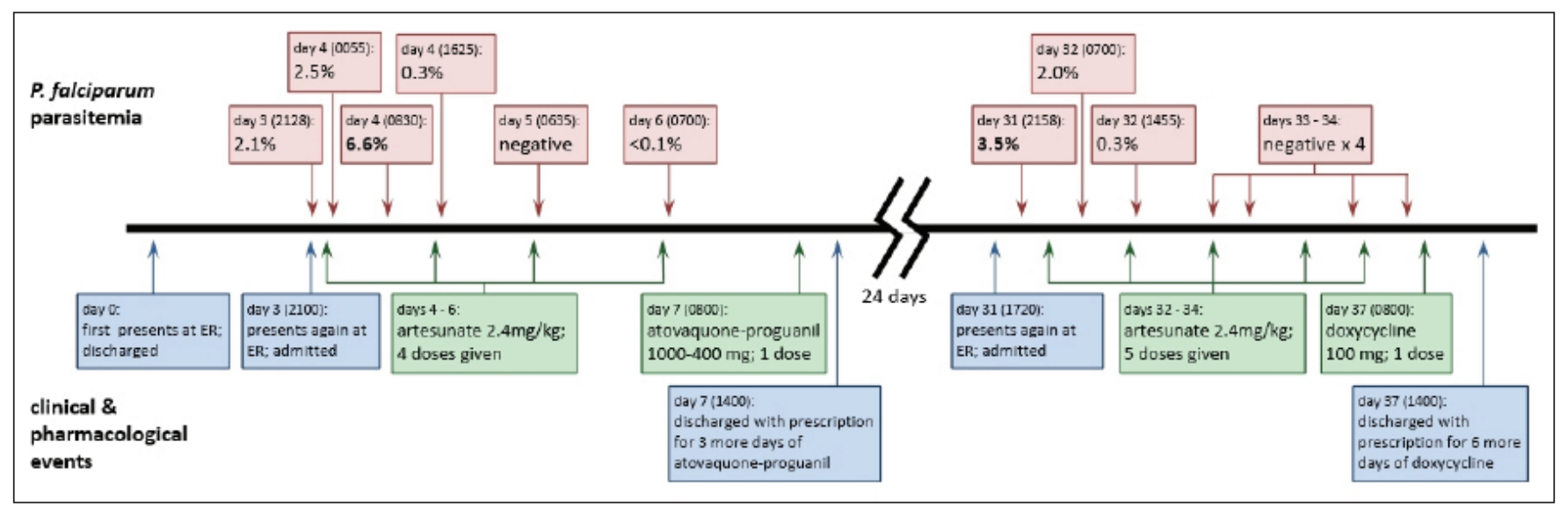

Figure 1) Clinical, pharmacological and parasitological timelines of events in patient's course. ER Emergency room; P falciparum Plasmodium falciparum

orally twice per day for seven days). The patient showed marked recovery within $48 \mathrm{~h}$, and insisted on leaving on day 37 . When seen in follow-up on day 38 , she was completing her course of doxycyline and was doing well. Figure 1 summarizes her clinical course.

In an effort to determine whether this was a treatment failure due to genetic alterations in putative markers of artemisinin resistance, molecular detection of pfmdrl copy number and mutations in cytb (malarone resistance), pfcrt (chlroqouine resistance) and $p f m d r 1$ (artesunate and mefloquine resistance) were conducted (2-4). The original and recrudescent malaria specimens were analyzed using real-time polymerase chain reaction and $p f m d r 1$ copy number was calculated relative to the chloroquine-sensitive strain $3 \mathrm{D} 7$ as 0.89 and 0.93 , respectively. DNA pyrosequencing confirmed the following haplotype in the recrudescent isolate: cytb Y268, Pfcrt K76, Pfdmr1 N86Y, Y184, S1034, N1042 and D1246 (5). Further investigation of pharmacy records revealed that the patient did not fill the full atovaquone-proguanil prescription as an outpatient but did fill the doxycyline prescription. This suggests that failure of adherence to the follow-on drug was responsible for treatment failure in the present case. It is well described that the rapid-acting nature of artemisinin derivatives require a partner drug, with previous reports of up to a $50 \%$ recrudescence rate following artemisinin monotherapy $(6,7)$. It is, therefore, likely that artesunate combination therapy was the appropriate treatment in this patient from Africa, and that adherence to the accompanying oral drug as an outpatient is critical to avoid treatment failure. Given the potentially dire outcomes of $P$ falciparum infection and, even more ominous, the spectre of widespread artemisinin resistance, measures should be taken to improve adherence, including consideration of direct observation of the administration of artemisinin derivatives and their partner drugs in settings where this is practical. Emphasizing the importance of completing the course of therapy with the patient and their caregivers should be undertaken, optimally with adequate language translation. Providing the patient with the full course of tablets rather than a prescription at discharge may minimize the barriers of finances and transportation. Finally, close follow-up, which may include a visit at one week postdischarge to ensure adherence and another at four weeks postdischarge, is key to detecting treatment failure or recrudescence early, and to swiftly manage these situations to avoid the risk of subsequent morbidity and mortality.

ACKNOWLEDGEMENTS: The authors thank the clinical laboratory staff for their expert technical assistance.

DISCLOSURES: The authors have no conflicts of interest to declare.

\section{REFERENCES}

1. Canadian Recommendations for the Prevention and Treatment of Malaria Among International Travellers - 2009. Public Health Agency of Canada website. <www.phac-aspc.gc.ca/publicat/ccdrrmtc/09vol35/35s1/index-eng.php> (Accessed March 4, 2013).

2. Korsinczky M, Chen N, Kotecka B, Saul A, Rieckmann K, Cheng Q. Mutations in Plasmodium falciparum cytochrome $\mathrm{b}$ that are associated with atovaquone resistance are located at a putative drug-binding site. Antimicrob Agents Chemother 2000;44:2100-8.

3. Reed MB, Saliba KJ, Caruana SR, Kirk K, Cowman AF.

Pgh1 modulates sensitivity and resistance to multiple antimalarials in Plasmodium falciparum. Nature 2000;403:906-9.

4. Fidock DA, Nomura T, Talley AK, et al. Mutations in the P. falciparum digestive vacuole transmembrane protein PfCRT and evidence for their role in chloroquine resistance. Mol Cell 2000;6:861-71.

5. Zhou Z, Poe AC, Limor J, et al. Pyrosequencing, a high-throughput method for detecting single nucleotide polymorphisms in the dihydrofolate reductase and dihydropteroate synthetase genes of Plasmodium falciparum. J Clin Microbiol 2006;44:3900-10.

6. Meshnick SR, Taylor TE, Kamchanwongpaisan S. Artemisinin and the antimalarial endoperoxides: From herbal remedy to targeted chemotherapy. Microbiol Mol Bio Rev 1996;60:301-15.

7. Rosenthal PJ. Artesunate for the treatment of severe falciparum malaria. N Engl J Med 2008;358:1829-36. 


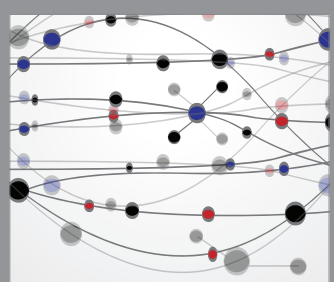

The Scientific World Journal
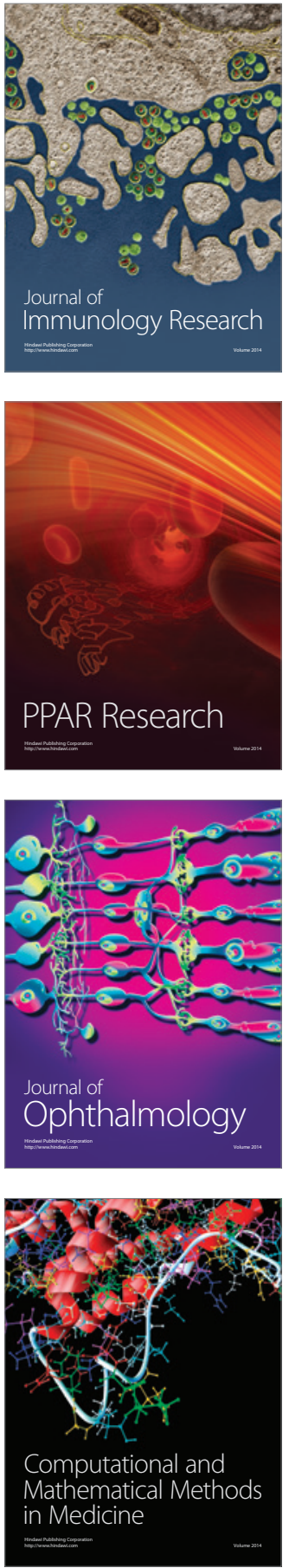

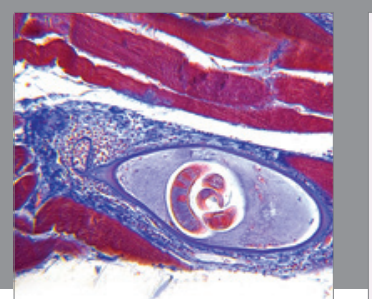

Gastroenterology Research and Practice

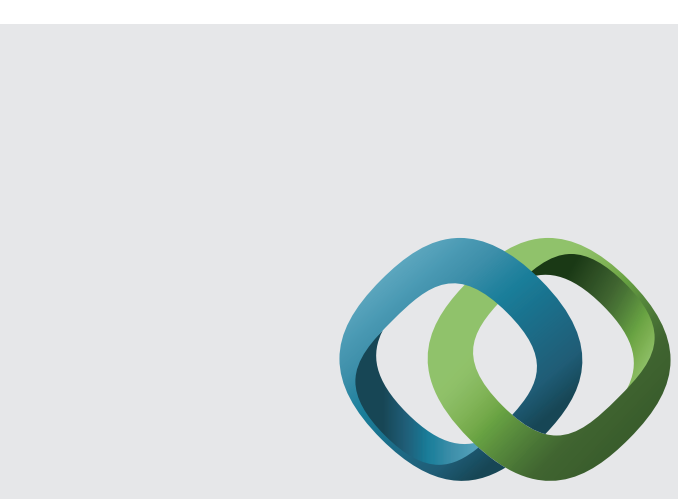

\section{Hindawi}

Submit your manuscripts at

http://www.hindawi.com
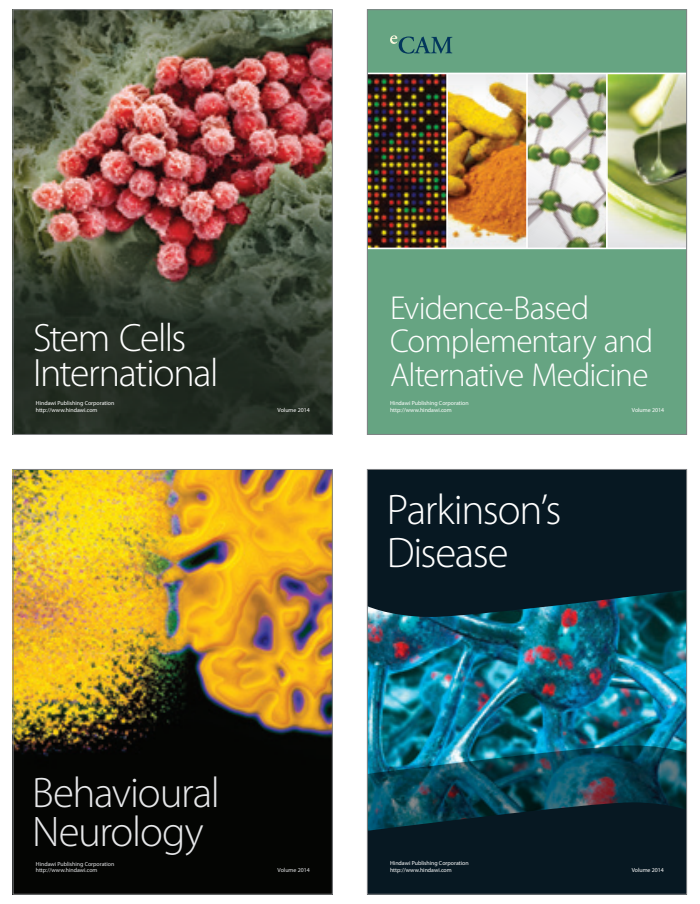
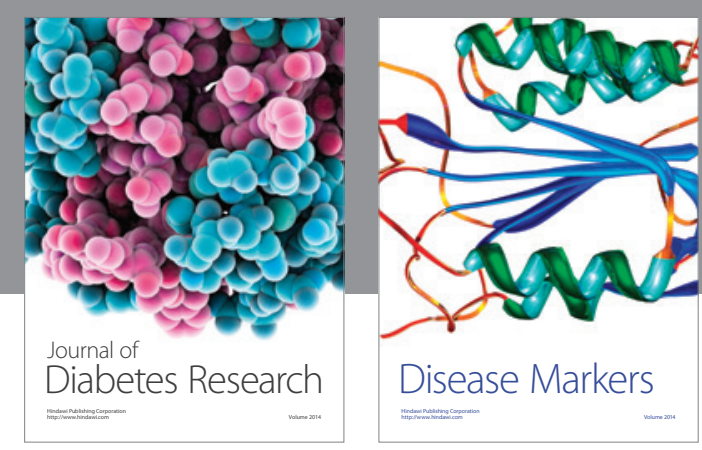

Disease Markers
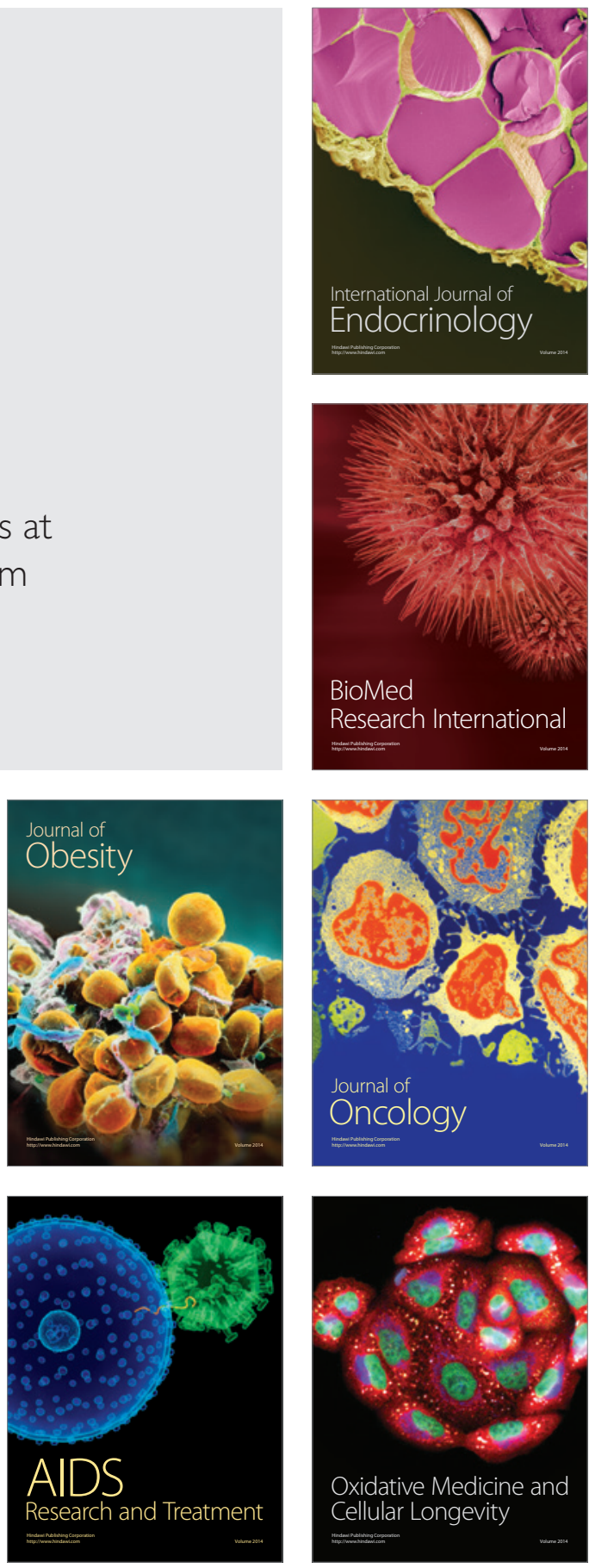